to the majority of plans proposed for their cure. I have put issues in, and kept them running for many months, but without ever being able to trace the slightest benefit; and here again $I$ think pathology teaches us to expect such a result, for we frequently meet with two or more sores on the same limb, and yet one does not exert a favourable influence on the other, which ought to be the case if the principle of using issues were correct.

Mr. Skey's pamphlet, emanating from so high a quarter as St. Bartholomew's Hospital, promised such great things, and with so much confidence, from the use of opium in the treatment of ulcers, that although the facts seemed to me to be meagre, and the reasoning feeble, I was hardly prepared to find, after a prolonged and extensive trial, that in no one instance was $I$ able to trace the slightest benefit from its use. It is true, it was a little surprising to find an old remedy suddenly endued with new and life-giving properties; it was enough to convert the ulcerated portion of the community into opium-eaters, such vigour was promised to their capillary systems. But, unfortunately, this little book, like many such professional ignes fatui, with which the profession are allured from time to time, has been tried at the bar of experience and found wanting; and my own firm conviction is, after trying opium in above forty cases, that it is utterly valueless in the treatment of ulcers of the lower limb.

When Mr. Spendor first published his book, I tried his chalk ointment in five or six cases, but I found such an accumulation of discharge, and so little progress towards a cure, that $I$ gave it up. I am willing to admit I may not have selected suitable cases for the experiment, and that $I$ may have given it too limited a trial; certain it is, that in my hands it was very unsuccessful. Mr. Syme's plan I have tried with marked benefit. The blister acts beneficially on the surrounding induration, and rapidly alters for the better the condition of the sore. The root of the evil is here attacked, and as might be expected, with good effect as regards the ulcer. It is, however, open to some objections; it is very painful, and patients are unwilling to submit to it-more particularly to its repetition: its good effects are sometimes only temporary, the case becoming as bad as ever again. It is apt to produce a permanent state of irritability of the skin. This last is the most serious evil resulting from it. I am glad to find, that in a notice of this gentleman's essay upon the subject, in the last number of the British and Foreign Medico-Chirurgical Review, after a fair and impartial estimate of the merits of the plan, a strong opinion is expressed that it will not bear a comparison with mechanical support, when efficiently and scientifically applied. They meet Mr. Syme's argument respecting the greater economy of his plan by the very just observation, that mechanical support, though apparently expensive, yet inasmuch as it enables the patient to pursue his ordinary a vocations, is far cheaper than any plan requiring rest. When they state the expense of each dressing to average a shilling, they very much over-estimate the matter-sixpence is a very liberal allowance, as I know by ample experience in the treatment of gratuitons patients.

The next point for consideration is the method I propose to adopt in the management of these chronic ulcers; but as this involves considerable detail, I must reserve it for my next lecture.

\section{ON THE TREATMENT OF ASIATIC CHOLERA BY THE ADMINISTRATION OF CALOMEL.}

\section{Br JOSEPH AYRE, M.D., Hull.}

I HAve within these few days returned from a visit $I$ have paid to Hamburgh, whither I had gone to inspect the cases of cholera, and inquire concerning the treatment pursued in it. The result of my observation upon the disease, and upon the appearances after death, confirmed me in the conclusion I had come to, that the disease was the same in its degree of malignancy, and in the pathological conditions which charac. terize it, as it was when I witnessed it in 1832; and with regard to the treatment employed for it, I regret to add that it is the same, variously modified, but still the same, which formerly, and judging from the account circulated, is again to win the confidence, feeble as it is, of the practitioners of this country, and with the prospect of realizing the same unhappy result which I witnessed in Hamburgh-namely, of a mortality of nearly three-fifths of the numbers attacked. The intensity of the disease and the treatment for the disease being the same in both countries, the result will be the same; and it was under the fullest conviction which a large experi- ence could give me that such a mortality might be very, very greatly lessened, that I ventured to recommend to my medical brethren at Hamburgh another and very different practice from that which they followed, supplying them with proofs of its success. It is with the same desire of promoting the general good that $I$ purpose to bring under the notice of your readers the mode followed by me in the treatment of the Asiatic cholera in 1832, and the evidence of its success.

I must begin by observing, that from the view which I had taken of the pathology of the English cholera, as explained in my work on the subject, and published in 1818, I had been led to the conclusion that the Asiatic form of it was merely an aggravated type of the European complaint, and was led to believe that the same treatment which I had so long pur. sued and recommended in the one, would, under a more active use of it, be an efficient remedy in the other. And I was the more strengthened in this conjecture from having had to treat on epidemic cholera in 1817 , which put on, in a few cases, the severer symptoms of the present epidemic, and only yielded to a more active use of the means which $I$ an presently to notice. Under the influence, therefore, of my preconceived impression regarding the probable efficacy of the treatment to both forms of the disease, but qualified in the same amount of the dose and the frequency of its repetition, on the appearance of the disease in Sunderland, in 1831, I proceeded to that town, and having suggested my views to Dr. Clanny, of that town, he very handsomely invited me to take charge of a patient whom he lad just been called to, whom I found in the act of being bled, who was already livid and of a death-like coldness, and whose pulse became extinguished immediately after the bleeding. To this patient so committed to my care I gave two grains of calomel and two drops of laudanum every ten minutes. I saw her again after a few hours, when I found the pulse had returned to the wrist. Having to visit Newcastle the following morning, I left my patient under the care of Mr. Embleton, the cholera surgeon, and, on my return two days after to Sunderland, found my patient quite recovered. In Newcastle, the saline and other modes of treatment, as novel as they were incongruous, were in full use, and it was not until some time, and after the failure of all other means of relief, that the plan I suggested obtained a pretty general adoption in that town. At the time of my visit to Sunderland, the disease was about to disappear, and the case I treated was among the last that occurred there. In a few months the complaint broke out in this town, and the first case was in a man residing in a locality near the river. He fell under the care of my friend, the late Dr. Chalmers, to whom, as well as to the other professional gentlemen of the town, I communicated my plan of treatment, and who, adopting it, succeeded in curing the patient. It was a case in which the lividness and coldness of the surface, and the other characteristic symptoms of collapse, were present. It was seen by a great number of the profession, and the treatment was early commenced. The next case was of a child of seven or eight years of age. It was one of collapse, and under the care of the cholera surgeon, who treated it with single grain doses of calomel, and it also recovered. Neither of these cases, as I have stated, were under my care, but were treated agreeably to $\mathrm{my}$ plan, and had been fully under my notice. The next case so treated was the wife of a sweep, of drunken habits, to whom I was called by Mr. Sharpe, and whom I found in extreme collapse, livid, cold, and pulseless. The treatment used was two grains of calomel every ten minutes, with three or four drops of laudanum. Mr. Sharpe and I remained with her a considerable time, and his assistant continued with her through the night to secure punctuality in the time of exhibiting the medicine. In the morning, at my visit, I found the pulse restored, and the violence of the collapse subdued, and in a few days she was well. In a day or two after this case, I saw another with Mr. Sharpe, and which was nearly as severe as the last, and was saved by the same treatment.

I could now reckon up five cases, and only five, which I knew had been treated conformably to my views, three of which had been under my care, and two within my knowledge, all the five having been in extreme collapse, and all recovered. At this time there had been sixty-five cases of the disease reported to our Cholera Board, of which forty had been fatal, and only twenty-five followed by recovery.

The next case, forming the sixth which came under my method of treatment, was one which was visited by two of the medical gentlemen, one of them being a physician who had been much engaged in treating the disease, and who relied, I believed, on what was termed the saline treatment. The case was one of a young girl, about fifteen years of age, 
who was, as they believed, in a thorougly hopeless state of collapse, and of whom, on this account, they declined to take charge, but dirceted that $I$ should be sent for to her; and I regret for their sakes to have to add, in scorn of any attempt I should make to save her. Some time was lost before I could visit her, and it was with a hope against hope that I laid myself out to do my utmost to save her, by visiting her almost hourly; and I did save her, and to the extent of bringing her out of the collapse, and progressively, during ten days, to a state of nearly entire convalescence, when some egregions irregularity in diet, and in the indulgence of some sour oranges, set up an irritation in the stomach, which ended in water of the brain. My success in this case, and in several others which immediately followed it in this district gave me at once an ample field to test to my utmost wish the value of my practice. The cases $I$ had to treat were of varying intensity, but nearly all were, like those whose recoveries I have related, livid and cold, and many of them nearly or entirely pulseless. Fully three-fourths of the first hundred of my patients were seen by Mr. Sharpe or his assistant by whom I was greatly assisted in the treatment, and for some time subsequently by the hospital assistants, and particularly by $\mathrm{Mr}$. Hunt, who saw and attended many of them. Calomel in one or two grain doses, taken with one or two drops of laudanum, and repeated every five or ten minutes, for several successive hours, with an occasional omission of the laudanum at intervals, formed my exclusive remedy for the blue or collapsed stage in all the cases I attended. I scarcely used a single auxiliary means of any kind. I neither bled, nor gave stimulants, nor emetics, nor used the air-baths, nor frictions, except to relieve the cramps, nor did I resort to any but the ordinary means for supporting the temperature or strength of the system. I gave only calomel, and in the dose and manner described, and placed no other limit to the use of it than that which was placed by the disease. So long as the disease in the collapsed stage continued, the medicine was continued; for pending the duration of that stage, I desire emphatically to aver, no absorption of the calomel takes place, and no ptyalism can occur; and when that stage was yielding to the remedy, I took the needful care to suspend the use of it. Of the patients whom $I$ lost, the greater number died in the stage of collapse, and within from twelve to twenty-four hours from my first seeing them; and nearly all, if not all, from causes which were superadded to the disease, and which, in most instances, might have been obviated by a more exact attention of the friends and attendants to their duty. Few, therefore, died in the consecutive fever, and of those who recovered, not one in ten had any fever at all; for it is one of the essential and distinguishing properties of this treatment, to prevent the occurrence of the consecutive fever, by its direct power to restore the secretion of the liver, and which is alone required to put an end to the disease. I have already stated, that notwithstanding the very large quantities of calomel that are often needed, and taken in single grain doses, ere the collapse is subdued, no ptyalism or other inconvenient effect is ordinarily produced by it. Not one in twenty of my patients had any ptyalism at all; nor in the very few who had it did it last much more than a week, and not in any of them was there a vestige of it at the end of a fortnight. Indeed, after taking some pains to call to my recollection the number of such patients, I can only count up seven who could be said to make any complaint of it, and with those whose lives had been saved by it, it passed away entirely in ten or twelve days, and without producing, or leaving behind it, even the shadow of a shade of those effects which some might imagine to be inevitable, and in its anticipation bewail with profitless lamenta. tion. In the way already described, I gave it alike to infants, though in a smaller dose, and to the aged, and in one instance to a considerable extent to a woman ninety-two years of age, whom I found in the collapse stage, and nearly pulseless, who in a few days was wholly recovered, and who survived the attack no less than eleven years, having reached the advanced age of one hundred and three, and with a power to take outdoor exercise up to a period very near her death.

In some cases it was taken in quantities the most considerable, and which nothing but the imminency of the danger from the disease, and the experience of its harmlessness, could justify. By one man, Vaughan, a tramp, who was admitted into the hospital in the stage of collapse in its most malignant form, and who only emerged from it slowly at the end of three days, the immense quantity of five hundred and eighty grains of calomel were taken, and who, notwithstanding, without either fever or ptyalism following, was perfectly well, and ready to leave us in a week.

And now, Sir, having given this brief and hasty sketch of the course of treatment which $I$ have pursued in the Asiatic cholera, it remains for me to bring under the notice of your readers, as a means of judging of its value, a comparison of he results of the treatment by small doses of calomel, when contrasted with other modes. And here, Sir, while disclaiming all desire to undervalue the zeal or ability of others, $I$ feel that the interests of truth demand of me to make no compromise with error, or forego every honourable method to expose it. I have now before me the records of our Hull Board of Health, in which are registered the names of every patient, and of every medical attendant respectively, with the date at which the treatment began, and its result. These records now form the materials for history, and it was with a view so to employ them, that I procured, and have to this hour preserved them; and I find, selecting from them at random, and taking the period when the disease was most rife with us, that from the 5th to the 7 th of July, inclusive, there were fifty-two fresh cases, of which twenty-nine were under mine and Mr. Sharpe's care, with only seven deaths, while the remaining twenty-three were variously treated, and of these fourteen were fatal. But, again, from the same records, I take the account of the patients from the 1st to the end of October, when the disorder left us, and I find that during this period there were twenty-nine fresh cases, of which twenty came under our care, while the remaining nine fell under the treatment of others who did not adopt that pursued by us; and of the twenty patients treated by us only four died, whilst of the remaining nine only three recovered. In making these comparative statements, I am aware that $I$ lay myself open to the charge of invidious dealing with those who were my contemporaries sixteen years ago, but I trust to find a justification in the high and urgent purpose of bringing under public notice a means by which much of the fatality of this fearful disease may be averted, and the difficulty of subduing it be greatly lessened. And here I must further observe, that before I had had any of the subjoined communications made to me, or any expectations of becoming possessed of a copy of the records of our Board of Health, and pending the continuance of this disease in the town, I judged it advisable to obtain the testimony of others in aid of my own, and who should, from their own observation, be enabled to judge of it. For this purpose I applied to the then corporate body, with the request that they would form a committee of six gentlemen three of whom to be of my profession, and who, in pairs, should visit every patient I had, and report the state of the case, together with the treatment and results. This application, for reasons unexplained to me, having been declined, there remained for me only the expedient of soliciting some three of my medical friends to undertake that office, and I was fortunate enough to secure for this purpose the late $\mathrm{Mr}$. Jenkins, a retired halfpay naval surgeon; Dr. Henesey, and Mr. Marston, then both of this town. These gentlemen, at my request, visited, either separately or together, all the patients which from that time came under my care, and when the disease had entirely left us, the letter which follows was aảdressed to me by them in answer to an application which I made to them on the subject. After this letter, and the testimonial of Mr. Sharpe, confirmatory of the sentiments expressed by my other colleagues, will be found the testimony of several gentlemen from different parts of the kingdom, and which was either communicated to me by letter, or communicated to the medical journals. In bringing this communication to a close, I feel that there are many points in the treatment, and in the rationale of it, which wonld admit of further remarks from me; but the extent to which I have trespassed on the pages of THE LANCET, and on the attention of its readers, compels me to bring them to an end; and I shall content myself with giving a summary account of the numbers of my patients, and the circumstances which precluded the recovery of those of them who died, and referring to the testimony subjoined.

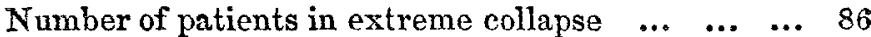

severe collapse...

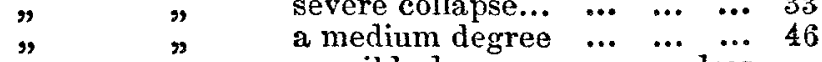

$" \quad$ " a mild degree, more or less

" $\quad \begin{gathered}\text { advanced } \ldots \\ \text { having symptoms of impending }\end{gathered}$ collapse, with cramps, \& the characteristic discharges ...

Total 219

Recoveries, 176; Deaths, 43 
of the deaths-

There were of those who were dead, when I first went to visit them, but whom $I$ was required to report of, and of others who were dying, and either could not, or did not, use any means $\quad \ldots \quad \ldots \quad \ldots$

Of those in whom the treatment was most negligently carried on by the attendants, or wholly neglected... Of those in whom there was previous disease ... $\quad \ldots$ Dropsy of the brain supervening, with neglect... ....
Relapse from palpable disregard of care in the diet...

$$
\begin{array}{lllllll}
\text { Total } & \ldots & \ldots & \ldots & \ldots & \ldots & 43
\end{array}
$$

\section{Copy of a Letter from Messrs. Jenkins, Henesey, and} Marston, to Dr. Ayre.

Dear Sir,-We have received your letter, in which you request us to state, first, to what state of intensity has the stage of collapse arrived in the cases of cholera which we have seen recover under the treatment of small and frequent doses of calomel, and whether any of the recovered cases had been pulseless; second, what were the circumstances which appeared to us to preclude the recovery of the four patients whom you have lost in this second appearance of the complaint? third, whether it has occurred to us to know if any patient has passed into the stage of collapse, for whom either you or we have prescribed in the premonitory stage? and fourth, and lastly, what are the conclusions which we have formed with respect to the power of calomel so given in arresting the impending collapse, and in subduing it when established? To which inquiries, from our having, either singly or together, seen all the cases of collapse which you have attended since the disease re-appeared, we beg to reply, that we have witnessed the recovery of patients from a state of collapse that was most entire, and of great intensity, as characterized by the sunken eye, the livid surface, and cold tongue, the cold, shrivelled, and sodden hands, the hoarse, choleric voice, violent cramps, rapid and scarcely perceptible, and in two cases extinguished, pulse, and the long and complete suppression of the secretion of the kidneys; and that in the case of the four patients who died, there was either neglect in sending for advice in anything like a reasonable time, or great neglect in giving the medicine. That we have never met with or heard of a case proceeding into the stage of collapse, for whom either you or we had prescribed in the premonitory stage, and we do not believe that such a case has occurred; and our conviction, therefore, in regard to the power of calomel, when given in small and frequent doses, is, that it will in every case arrest the disorder in its premonitory stage, and will cure nearly all, if not all, the early cases of collapse, and a considerable proportion of those where the collapse is entire, and even in some cases where the pulse is not to be felt at the wrist; though we do not mean to say that cases may not occur of such extreme malignity as to defy the power of this treatment, yet we are disposed to think, from what we have seen, that the main cause of its failing would arise from the collapse having been allowed to acquire such a power as to overwhelm the vital functions, and to render the stomach insensible to every agent thrown into it. (Signed)

RrchaRd Jankins, ] Members of Edward Henesey, the College o To Dr. Ayre. Hentry Marston, $\}$ Surgeons, \&c.

\section{From R. Sharpe, Esq.}

Having seen a great deal of the Asiatic cholera during its prevalence in 1832, and having attended a large number of patients both with Dr. Ayre and alone, and having pursued the practice adopted by him, I feel no difficulty in asserting, that my experience of the efficacy of the treatment is in entire accordance with the opinion above expressed by the Messrs. Jenkins, Henesey, and Marston. (Signed) Rrohard Sharpe, M.R.C.S. \&c.

\section{From Mr. Wilson, of Sheffeld, to Dr. Ayre.}

$$
\text { Feb. 1833, Sheffield. }
$$

SIr,-In compliance with your request, we beg to transmit to you the result of our treatment of cholera; which plan of treatment was adopted from your system of giving small and frequently repeated doses of calomel, and which you will find, on comparing the number of deaths with the recoveries, to have been successful, and satisfactory to a high degree.

(Signed, for Wright \& Self) KNowLtoN WIIsoN.
Total number of deaths .......................... 23

Of those who reached the collapsed stage ...... 54

Of those who had the disease clearly developed 28

Of those who had premonitory symptoms to a

greater or less extent .............................

Total ...................... $\overline{103}$

Out of the twenty-three who died, we may remark, that in five the medicine was given with the greatest irregularity; that four had been on our sick list for many days previous, ill of other disorders-one, for instance, in typhus; three were confirmed drunkards; and, lastly, one was nearly eighty years of age; therefore, it would be seen, that out of the twenty-three individuals, with whom the disease proved fatal, the medicine had only a fair chance in producing its effect in ten. It may, perhaps, be worth relating, that in one case we gave the calomel to the extent of 300 grains.

(Signed) K. W.

Extract of a letter from P. Glenton, Esq., of the Choler a Hospital, Newcastle, dated January, 1832.

"Calomel has been given to a considerable extent, in the dose you mention, and, as regards my own own experience, it is a medicine deserving the highest praise, both in the treatment of the primary and consecutive stages of this tremendous disease."

\section{Extract of a letter from W. Hardcaslle, Esq., of Newcastle,} dated February, 1832.

"Calomel has been our sheet anchor when administered according to your plan, every ten or fifteen minutes. It has been eminently successful."

\section{Extract from the letter of a Correspondent from Sheffield,} dated, November, 1832.

"I had been for some time engaged in observing the nature of the malignant cholera at the liospital, and was quite disappointed and grieved at the results of the treatment, before a case presented itself in my own practice. It occurred in the person of a cleanly and respectable poor woman, Mrs. $\mathrm{K}-$, aged 63 . The existing symptoms were, rice-water dejections, moderate cramps, fceces et vox cholerica, with complete prostration of strength. Pulse at the wrist just perceptible; and incessant retching. At ten in the morning she took one grain of calomel, with two drops of laudanum with camphor mixture, every five minutes until nine in the evening, when the character of the evacuations were satisfactorily changed, and the vomiting had ceased. I ordered the calomel to be given only every half hour; on the next morning, a complete relapse had resulted, the evacuations were like rice-water, and the stomach irritable. A resumption of the calomel wos ordered every five minutes throughout the day. In the evening, $I$ was gratified on finding a great amendment in the symptoms. My next case was a woman, aged 52, whom I bled moderately; symptoms very like the former, but with more severe cramps. She took one grain of calomel with laudenum every five minutes for forty-eight hours; a blister was applied to the epigastrium. She improved rapidly for a week, and a relapse from cold again occurred, and again yielded to the small doses of calomel. Eventually she was cured without any soreness of the mouth. This patient took 576 grains of calomel. The writer proceeds to state that he had succeeded in many other cases, and that other practitioners of that town had adopted my practice, and with the like success.

\section{Report from the Cholera Hospital at Liverpool.}

In the stage of collapse, the most beneficial course has been the exhibition of calomel in small, frequent, stimulating doses. We have tried every mode of treatment, from the saline remedies to the allowance of cold water ad libitum, and have been compelled to discard them in favour of the plan of which you have an outline.

\section{Abstract of Documents communicated by the Central Board} of Health.

Cholera Irospital, Nutford-place, London, Oct. 1st.

The disease here under the care of Dr. Arthur T. Holroyd, of Harley-place, has almost universally yielded to the treatment recommended by Dr. Ayre, of Hull. The house-surgeon, Mr. Toynbee, has been indefatigable in his attentions to the patients, and I attribute, observes Dr. Holroyd, my success, in a great measure, to his exertions. He suffered from a severe 
attack about two months ago, but fortunately recovered under the use of calomel and opium. One of the nurses and the porter were also attacked, and restored to health by the same remedies.

\section{Extract from a Return of Patients admitted into St. Pancras Hospital, London.}

In severe cases the saline treatment was employed, not only without mitigation of any one symptom, but with injurious effects. In not one case did the saline treatment produce recovery. Calomel and opium, however, afterwards restored the patients in some instances. One man, John $\mathrm{H}-$, was most severely attacked on the 2nd of September. He was treated with calomel and opium, (muriate of morphia,) of the former of which he took 800 grains, and of the latter, thirty grains, withont their producing any ptyalism or head affection. He recovered on the 14 th of the same month.

\section{ON THE TREATMENT OF GONORHREA IN THE FEMALE.*}

\author{
BY R. G. MAYNE, M.D., \\ SURGEON TO THE LEEDS LOCK HOSPITAL.
}

(Continued from p. 148.)

THE notice of my former paper in one under the same heading by Dr. Egan, in The Laneet for September 2nd, p. 261, reminds me of my promise to offer, on some future occasion, a few observations, which the length of my first communication forbade me then to add. With permission, I will now briefly fulfil that promise, and afterwards proceed to weigh the strictures with which my opinions have been visited by Dr. Egan.

The views entertained by me on this subject were so lately detailed, that they can very easily be referred to, and therefore need not be now recapitulated. Another consideration which suggested itself, springing out of the same estimate of the true nature of gonorhroea in the female, acted on by me in its treatment, was the applicability of the copaibal solution as a remedy for gonorhrœal ophthalmy. This idea was soon put to the test both in private and in hospital practice, and the result was speedily and completely successful. I do not mean to state that in every case, and however high and extensive the attendant inflammation, this solution, alone, had power to effect a cure. As in gonorhroeal vaginitis and urethritis it is necessary first to reduce any excessive inflam. mation that exists, so in gonorhroeal ophthalmy, with a similar object, but in a more urgent degree when the mischief threatens the eye itself, may it be requisite to employ active counter-irritation, and rigorous antiphlogistic treatment. But when this protective object has once been attainedthat is, where the ophthalmic disease has either been brought back to, or has never encroached beyond, the proper limits of the conjunctival membrane, no matter how severely this was affected, the copaibal solution, alone, dropped between the eyelids three or four times a day, did, in a surprising manner, restore the parts to perfect health. I shall advert to but two cases in illustration.

A little girl, of about six years of age, had gonorhroal vaginitis, and, at the same time, ophthalmy, the conjunctival membrane being excessively engorged, of the brightest red, and a thick, muco-purulent matter profusely flowing from its surface, but as yet the various portions of the eyeball were unattacked by the inflammation. In this case the copaibal solution was applied between the eyelids, and the copaibal in. jection to the vagina; and under this very simple treatment alone, the child, who had been carried the round of all-promising quacks, prescribing druggists, \&c., for many weeks, and had been confidently doomed to hopeless blindness, steadily recovered from both complaints.

The other case was that of a young, robustions Irish labourer, the subject of gonorhroea, who was led to the hospital by the man he lodged with, his eyes in the most unsightly condition conceivable-not that the power of vision was lost, but he could not bear to expose to the light or air the intensely inflamed conjunctival surfaces. The vascular congestion was so excessive, and chemosis so complete, that when the lids were separated, there appeared an irregular mass, as of red-currant jelly, with a dark depression in the

* The publication of this paper ought to have preceded that of the letter of Dr. Mayne in The LANCET of last week, in which references were made that might not be understood without this explanation.-ED. L. centre, where the iris and pupil could, by a little searching, be distinguished. The man complained of no acute pain or uneasiness in the eyeball, of no severe special symptom of the mischief having proceeded farther than the conjunctival membrane; his case presented nothing more formidable, in short, than this avoiding of exposure of the irregular mass of highly congested membrane. The copaibal solution was applied, and in a few days the appearance of the eyes was much improved, but inflammation by this time became evident in the sclerotic cost and iris. The necessary treatment was instantly put in practice with success, and by then persevering with the copaibal application alone, the cure of the gonorhroal inflammation was in four or five weeks completed.

There is one other consideration, important in a physiological point of view, though not directly involved in the subject under discussion, to which I will here simply allude. It is, that gonorhroa in the female, when the uterus is implicated, which, as has been shown, it often is, must inevitably prove an obstacle to conception, according to the generally received and most intelligible theory of that mysterious act. It will prove such, mechanically, by the thick puro-mucous secretion which fills the cavity and neck of the womb, and may probably do so, pathologically, by the unnatural condition of the inflamed, thickened, and, of course, less accommodating mucous membrane. So far as one can form a judgment in such a matter, my own observation leads to the conclusion, that barrenness is attributable to this and to similar easily comprehended causes much more frequently than has ever been thought of

I have now to examine and weigh the strictures passed by Dr. Egan on my first communication. That gentleman begins by regretting that before committing my observations to the press, "Dr. Mayne had not an opportunity of reading in a connected form the paper upon which he comments, as in it I stated that the particulars of the cases were noted carefully and accurately in the presence of the patients themselves, and in no instance did I tmist to memory for a description of the symptoms enumerated. He would likewise have per. ceived that this statement was further corroborated by reference to a statistical table, containing the name, age, length of duration of disease, appearances presented on examination with the speculum, of all the patients submitted to inspection. For the accuracy of each particular I can fully vouch, having in the majority of instances alluded to instituted the same test on frequent occasions, lest there might have been any possibility of falling into error by a superficial or cursory examination." I believe I ought to feel greatly obliged to Dr. Egan for so fexlingly bemoaning my hapless ignorance of his, no doubt, excellent paper; but I really do not see that my own experience would have been set at naught, or that the judg. ment founded upon it would have been altered, even by themost careful and anxious perusal of that paper, which, by the way, not having seen, I had no intention of commenting upon, but only felt it right to notice the extract of it which fell in my way, because it touched on one particular part of the conclusions I had after much pondering arrived at - the extension of the disease into the neck and cavity of the uterus. Dr. Egan is not likely to be moved from his position by any expressed notions of mine; nor can he reasonably expect that the most imposing array of cases on paper, however carefully noted "in the presence of the patients themselves," should uproot the convictions of another who has employed his powers of observation in a similar direction, but with a different result. I cannot so reverentially regard "a statistical table," duly prepared for committal to the press, as at once to prostrate my own impressions before its mighty influence. On the contrary, I can suppose it possible-and there is nothing decidedly monstrous in the supposition-that Dr. Egan's calculations may have proceeded on erroneous premises, and of what value would they then be, although fully vouched by himself? Thus, I have been astonished to find, by specular examination, that a sound uterus, under certain conditions, gives out a thick yellow mucus, so like to the muco-purulent discharge from the same organ when affected by gonorhroal inflammation that the distinction is very difficult to be made. Again, it is not uncommon to meet with patients labouring under both leucorhroea and gonorhroea, and I strongly suspect that a species of the former may be a sequela of the latter disease of the vagina and uterine cavity, just like the persistent gleet, consequent on the same disease of the urethra. It is, moreover, notorious that leucorhroea often very closely simulates gonorhrœa, just as a gleet will, after undue excitement, take on for a space the complete character of the original discharge, 